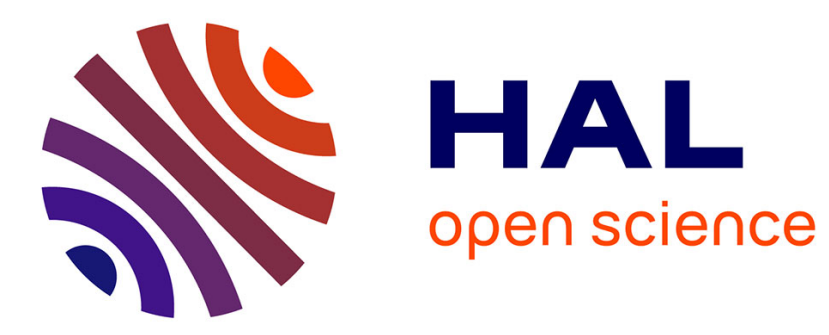

\title{
Palladium-Catalyzed $[3+2]-\mathrm{C}-\mathrm{C} / \mathrm{N}-\mathrm{C}$ Bond-Forming Annulation
}

Yang Liu, Zhongyi Mao, Alexandre Pradal, Pei-Qiang Huang, Julie Oble, Giovanni Poli

\section{- To cite this version:}

Yang Liu, Zhongyi Mao, Alexandre Pradal, Pei-Qiang Huang, Julie Oble, et al.. PalladiumCatalyzed [3 + 2]-C-C/N-C Bond-Forming Annulation. Organic Letters, 2018, 20 (13), pp.4057-4061. 10.1021/acs.orglett.8b01616 . hal-01957128

\section{HAL Id: hal-01957128 https: / hal.sorbonne-universite.fr/hal-01957128}

Submitted on 17 Dec 2018

HAL is a multi-disciplinary open access archive for the deposit and dissemination of scientific research documents, whether they are published or not. The documents may come from teaching and research institutions in France or abroad, or from public or private research centers.
L'archive ouverte pluridisciplinaire HAL, est destinée au dépôt et à la diffusion de documents scientifiques de niveau recherche, publiés ou non, émanant des établissements d'enseignement et de recherche français ou étrangers, des laboratoires publics ou privés. 


\title{
Palladium-Catalyzed [3+2]-C-C/N-C Bond Forming Annulation
}

\author{
Yang Liu, ${ }^{\dagger}$ Zhongyi Mao, ${ }^{\dagger}$ Alexandre Pradal, ${ }^{\dagger}$ Pei-Qiang Huang, ${ }^{\S}$ Julie Oble, $^{\dagger, *}$ and Giovanni Poli ${ }^{\dagger}, *$
}

${ }^{\dagger}$ Sorbonne Universités, Faculté des Sciences et Ingénierie, CNRS, Institut Parisien de Chimie Moléculaire, IPCM, 4 place Jussieu, 75005 Paris, France.

$\S$ Department of Chemistry and The Key Laboratory for Chemical Biology of Fujian Province, iChEM (Collaborative Innovation Center of Chemistry for Energy Materials), College of Chemistry and Chemical Engineering, Xiamen University, Fujian 361005, P. R. China.

Supporting Information Placeholder

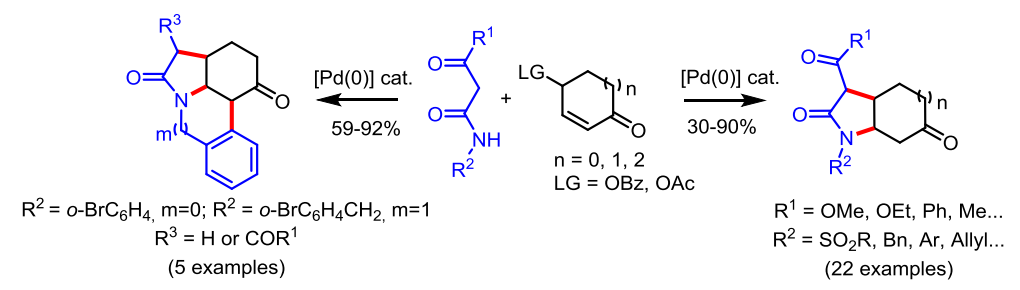

ABSTRACT: The synthesis of bi- and tri-cyclic structures incorporating pyrrolidone rings are disclosed, starting from resonancestabilized acetamides and cyclic $\alpha, \beta$-unsaturated- $\gamma$-oxy-carbonyl derivatives. This process involves an intermolecular Tsuji-Trost allylation / intramolecular nitrogen 1,4-addition sequence. Crucial for the success of this bis-nucleophile / bis-electrophile [3+2] annulation is its well-defined step chronology in combination with the total chemoselectivity of the former step. When the newly formed annulation product carries a properly located ortho-haloaryl moiety at the nitrogen substituent, a further intramolecular keto $\alpha$-arylation can join the cascade, thereby forming two new cycles and three new bonds in the same synthetic operation.

The efficient assembly of complex polycyclic structures in a single synthetic operation is a major endeavor for chemists, and domino reactions ${ }^{1}$ represent one of the most interesting ways to attain this objective with high step economy. ${ }^{2}$ In particular, annulation reactions, the most efficient methods for the generation of cyclic molecules, pioneered by O. Diels and K. Alder, ${ }^{3}$ and Sir R. Robinson, ${ }^{4}$ allow building up a cyclic structure through the concerted or stepwise creation of two new bonds from two separated components. ${ }^{5}$ In the frame of our current studies on $\eta^{3}$-allylpalladium chemistry and domino sequences, ${ }^{6}$ we recently reported the synthesis of hexahydroindole derivatives ${ }^{7}$ through Pd-catalyzed pseudodomino sequences ${ }^{8}$ using $\beta$-amido-ester as bis-nucleophiles and cyclic bis-allylic substrates as bis-electrophiles (Scheme 1, eq 1). ${ }^{9}$ Cyclic $\alpha, \beta$-unsaturated- $\gamma$-oxy-carbonyls represent another interesting family of bis-electrophiles, which can be engaged in synthetically interesting Pd-catalyzed cascades, as reported by A. Fürstner, J. E. Harvey, S. S. Ramasastry and R. Tong (Scheme 1, eq 2). ${ }^{10,11}$ Despite these works, the knowledge of the behavior of these bis-electrophiles is still far from mature. Herein, we disclose a $\mathrm{Pd}$-catalyzed cascade between resonance-stabilized acetamides and various cyclic $\alpha, \beta$-unsaturated- $\gamma$-oxy-carbonyls (Scheme 1, eq 3), which allows the achievement of a [3+2]-C-C/N-C bond forming annulation. $^{12}$ Importantly, the desired transformation is possible only if the intermolecular $\mathrm{C}-\mathrm{C}$ bond formation at the electrophilic $\gamma$ position (umpoled position with respect to the carbonyl function) precedes the intramolecular N-C bond formation at the electrophilic $\beta$ position. Furthermore, the use of acetamides bearing a properly located ortho-haloaryl moiety at the nitrogen substituent sets the stage for an additional intramolecular keto $\alpha$-arylation at the end of the cascade, thereby allowing the selective formation of two new cycles and three new bonds in the same synthetic operation (Scheme 1, eq 4).

Scheme 1. Domino reactions with bis-electrophiles and bisnucleophiles

Previous work

Pd-catalyzed sequences using cyclic bis-allylic substrates

$\mathrm{C}-\mathrm{C} / \mathrm{N}-\mathrm{C}$ bond forming

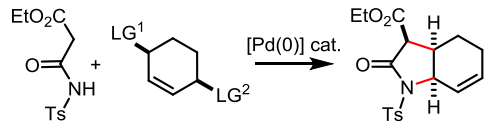

$P d$-catalyzed sequences using cyclic $\alpha, \beta$-unsaturated- $\gamma$-oxy-carbonyl derivatives $\mathrm{C}-\mathrm{C} / \mathrm{O}-\mathrm{C}$ bond forming
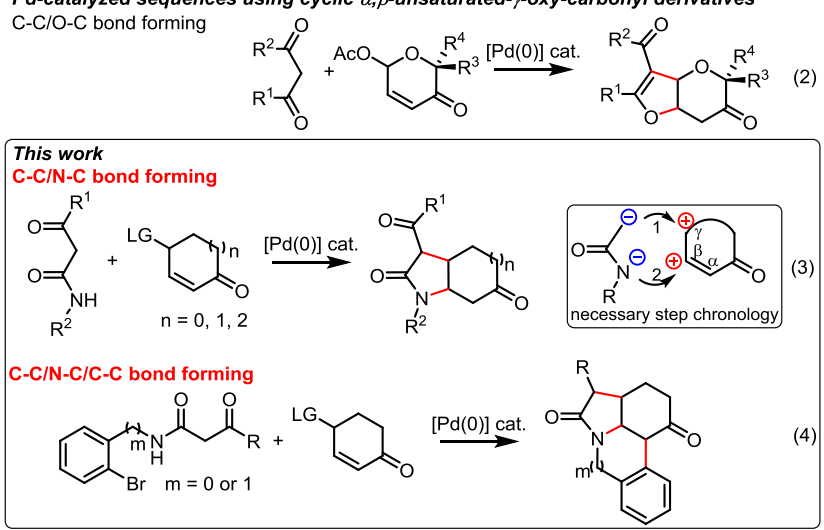
We started the investigation of this $[3+2]-\mathrm{C}-\mathrm{C} / \mathrm{N}-\mathrm{C}$ bond forming annulation using the $N$-tosyl amido-ester $1 \mathbf{a}^{13}$ and 2cyclohexenone 4-benzoate $\mathbf{2 a}^{14}$ as bis-nucleophile and biselectrophile model substrates, respectively (Table 1). The first test was performed using the conditions previously developed with cyclic bis-allylic substrates (Scheme 1, eq 1), ${ }^{7,9}\left[\mathrm{Pd}(\mathrm{OAc})_{2}\right.$ $(5 \mathrm{~mol} \%)$, dppb (10 mol \%), $\mathrm{NaH}$ (3 equiv) in $\mathrm{CH}_{3} \mathrm{CN}$ at 50 $\left.{ }^{\circ} \mathrm{C}\right]$. However, we obtained only a very low amount of the expected fused pyrrolidone 3a (18\% yield), along with a significant amount of phenol, arising from 2a through the elimination of the benzoate anion under basic medium. To suppress the formation of this by-product, the optimization of the reaction was performed in the absence of base, at room temperature, in THF $(0.1 \mathrm{M})$ and with a slight excess of biselectrophile $\mathbf{2 a}$ (1.3 equivalents of $\mathbf{2 a}$ relative to $\mathbf{1} \mathbf{a}$; see Supporting Information for detailed optimization). Subsequent screening of the palladium sources, such as: $\mathrm{Pd}\left(\mathrm{PPh}_{3}\right)_{4}$ (entry 1), $\mathrm{Pd}(\mathrm{OAc})_{2}$ (Table 1, entries 2-3), $\mathrm{Pd}_{2}(\mathrm{dba})_{3}$ (entries 4-5) or $\left[\mathrm{Pd}\left(\eta^{3}-\mathrm{C}_{3} \mathrm{H}_{5}\right) \mathrm{Cl}\right]_{2}$ (entry 6$)$ and the phosphine ligand $\left(\mathrm{PPh}_{3}\right.$ or $\mathrm{dppf})$, allowed us to reach the optimal conditions $\left[\operatorname{Pd}\left(\eta^{3}-\right.\right.$ $\left.\mathrm{C}_{3} \mathrm{H}_{5}\right) \mathrm{Cl}_{2}(5 \mathrm{~mol} \%)$, dppf $(15 \mathrm{~mol} \%)$ in THF at $\mathrm{rt}$ : protocol A], which led to the desired bicyclic pyrrolidone 3a in $90 \%$ yield (Table 1 , entry 6$)^{15}$

Table 1. Optimizations on the model bis-nucleophile/biselectrophile pair 1a / 2 a

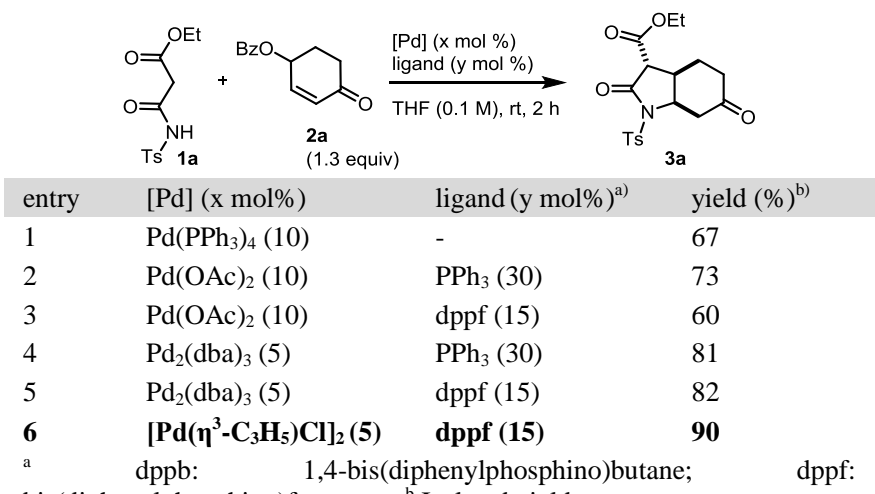

bis(diphenylphosphino)ferrocene. ${ }^{\mathrm{b}}$ Isolated yield.

With the optimized conditions in hand, the scope and the limitations of this $[3+2]-\mathrm{C}-\mathrm{C} / \mathrm{N}-\mathrm{C}$ bond forming annulation between the bis-electrophile $\mathbf{2 a}$ and a range of resonancestabilized $N$-sulfonyl acetamides 1a-f, modified at the sulfonyl or at the carbonyl substituents, were next investigated (Scheme 2). All the $N$-sulfonyl acetamides tested behaved satisfactorily (65-90\% yield), including acetoacetamide 1e, which afforded the expected annulated product as a $65: 35$ keto/enol mixture, whereas the $N$-triflyl derivative 1d did not show reactivity. In particular, in the case of $\mathbf{1 c}$ and $\mathbf{1 e}$, the reaction temperature had to be raised to $60{ }^{\circ} \mathrm{C}$, due to their manifest lower reactivity with respect to the other bisnucleophiles. It is worth noting that the annulation works satisfactorily when starting from the benzylated bisnucleophile 1f, too.

Different $N$-protections on the resonance-stabilized acetamides were next evaluated. Surprisingly, application of the above-optimized protocol to the $N$-carbamate bisnucleophile $\mathbf{1 g}$ did not afford the expected annulation product. After several trials and in deep contrast with our previous outcomes, we found that this type of substrate requires the presence of a base. A re-optimization effort established the following new conditions as optimal $\left[\mathrm{Pd}\left(\eta^{3}-\mathrm{C}_{3} \mathrm{H}_{5}\right) \mathrm{Cl}\right]_{2}(5 \mathrm{~mol}$ $\%)$, dppf (15 mol \%), DBU (2.0 equiv) in THF (0.1 M) at rt: protocol B] (Scheme 3).

Scheme 2. Variations of the resonance-stabilized $\mathrm{N}$-sulfonyl acetamide in the reaction with $2 \mathrm{a}$

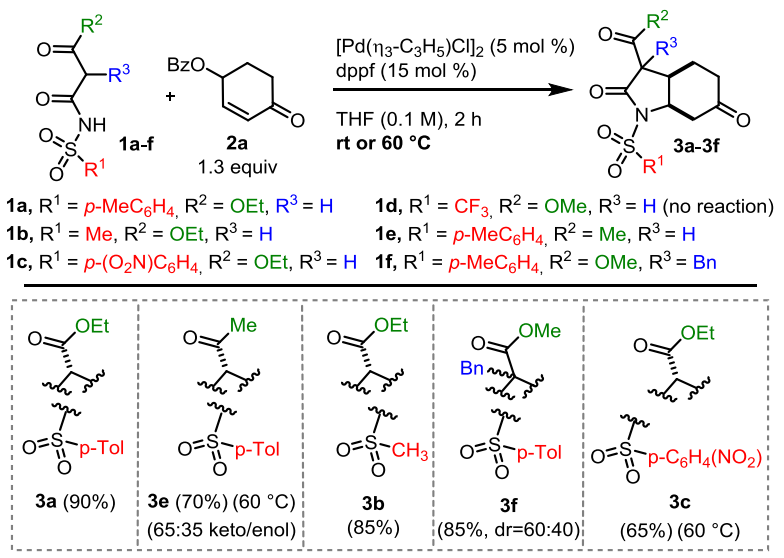

Scheme 3. Variations of the $N$-protection on the resonancestabilized acetamide in the reaction with $2 a$

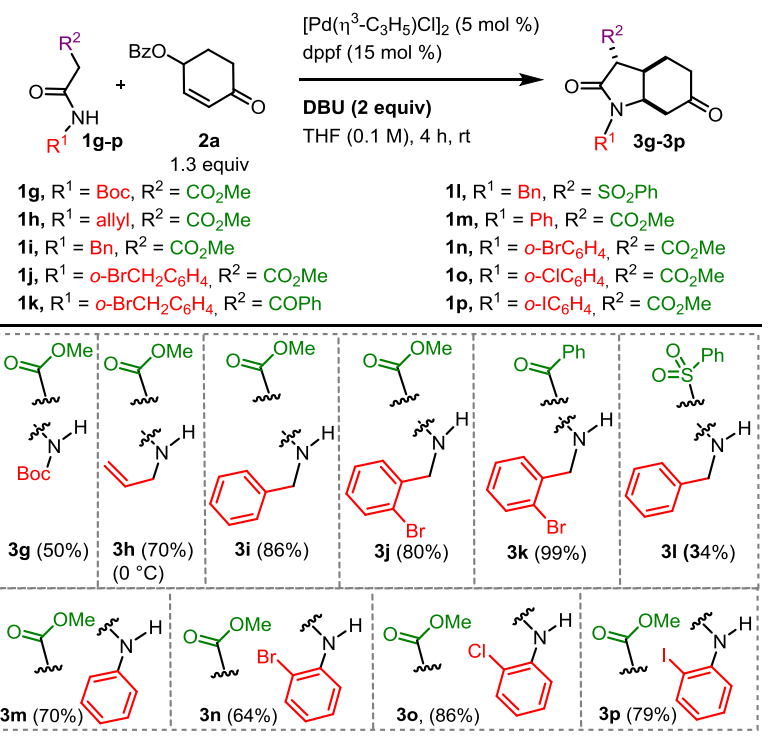

Under these conditions, the Boc derivative 19 afforded the expected product $\mathbf{3 g}$ in $50 \%$ yield. Good yields of annulated products were also obtained with $N$-allyl $(\mathbf{1 h})$, -benzyl $(\mathbf{1 i}, \mathbf{1 l})$, -o-bromobenzyl (1j, 1k), -phenyl (1m), -o-bromophenyl (1n), -o-chlorophenyl (10), - $O$-iodophenyl (1p) derivatives, carrying a methoxycarbonyl, a benzoyl or a phenylsulfonyl moiety as the resonance stabilizing group for the acetamide. In the case of $\mathrm{N}$-allyl amido-ester $\mathbf{1 h}$, the reaction must be performed at 0 ${ }^{\circ} \mathrm{C}$ for maximum yield. Interestingly, the $o$-bromo and $o$ chloro (but not the $o$-iodo) -phenyl substituted amides 1 n and 10 can react smoothly also in the absence of DBU, albeit in lower yields. This behavior is very likely due to the N-H acidity enhancement brought about by the highly electronegative bromine and chlorine atoms, which activate the nitrogen atom. ${ }^{16}$ The above results suggest that the acidity 
of the two mobile hydrogen atoms of the bis-nucleophile have to fit in an appropriate $\mathrm{p} K_{\mathrm{a}}$ window to allow the annulations.

Encouraged by these results, we next turned our attention to explore the $[3+2]$-annulation involving five- and sevenmembered cyclic $\alpha, \beta$-unsaturated- $\gamma$-oxy-carbonyls (Scheme 4). Treatment of cyclopentenone 4-benzoate $\mathbf{2 b}^{17}$ with 1a under the conditions of protocol $A$ gave the expected annulated product $\mathbf{4 a}$ in a very low yield. However, after substantial experimentation, we found that performing the reaction in toluene at $110{ }^{\circ} \mathrm{C}$ (protocol $\left.C\right)$ led to the annulation product $\mathbf{4 a}$ as a mixture of diasteoisomers (62\% yield). Under these new conditions and in the presence of DBU (protocol $D)$, the $N$-benzyl bis-nucleophile $\mathbf{1 i}$ furnished the corresponding annulated product $\mathbf{4 i}$, though in $49 \%$ yield. The seven-membered bis-electrophile $\mathbf{2} \mathbf{c}^{18}$ reacted smoothly under the original optimized conditions in THF. However, while reaction with $1 \mathrm{a}$ required heating at $60{ }^{\circ} \mathrm{C}$, reaction with $\mathbf{1 g}$ and $1 \mathbf{i}$ called for the presence of DBU at rt. As the Tsuji-Trost step is expected to be equally favored in all the cases studied, these experiments suggest that the intramolecular 1,4-addition step is easier for the 6-exo-trig and 7-exo-trig than the 5-exotrig ring closures.

Scheme 4. Variations of the cyclic $\alpha, \beta$-unsaturated- $\gamma$-oxycarbonyl

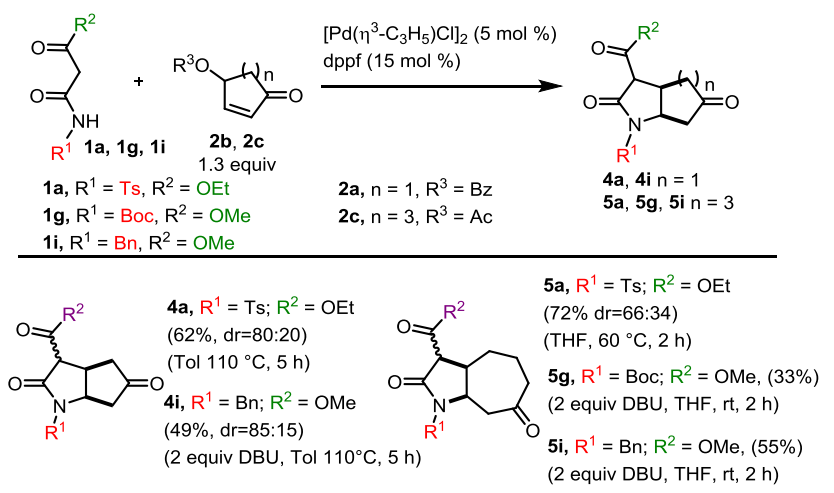

The use of cyclic $\alpha, \beta$-unsaturated- $\gamma$-oxy-carbonyls bearing a heteroatom was then investigated. We initially considered the formal incorporation of an oxygen or a nitrogen atom at position 6 of the parent cyclohexenone 4-benzoate (cyclohexenone numbering). However, preliminary experiments showed that $\eta^{3}$-allyl complexes deriving from substrates of this type have a strong tendency to $\beta$-eliminate leading to 2-pyrone or -pyridone, the driving force being very likely the aromatic character of these heterocycles (see SI). We therefore decided to consider the heteroatom at position 5 through the use of the 5-oxo-5,6-dihydro-2H-pyran-2-yl benzoate $2 \mathbf{e}^{19}$ in the presence of 1a. After several relatively fruitless trials, we found that the use of the above-optimized system in the presence of 2.2 equivalents of $\mathbf{2 e}$, provided the adduct $7 \mathbf{a}$ (30\% yield), which resulted from a second allylation taking place besides the "normal" allylation / conjugate addition sequence (Scheme 5, top). This result suggests that in this particular case, the initially formed adduct is more activated toward over-allylation than the starting bisnucleophile 1a. We speculate that an intramolecular $\mathrm{H}$-bond in the first generated intermediate $\mathbf{A}$ may be responsible of such original behavior. As expected, reaction of the benzylated $\beta$ - amido-ester 1f gave, under identical condition, the regular adduct $7 \mathbf{f}$ in satisfactory yield (Scheme 5, bottom).

Scheme 5. Reactivity of cyclic $\alpha, \beta$-unsaturated- $\gamma$-oxycarbonyls bearing an oxygen at position 5
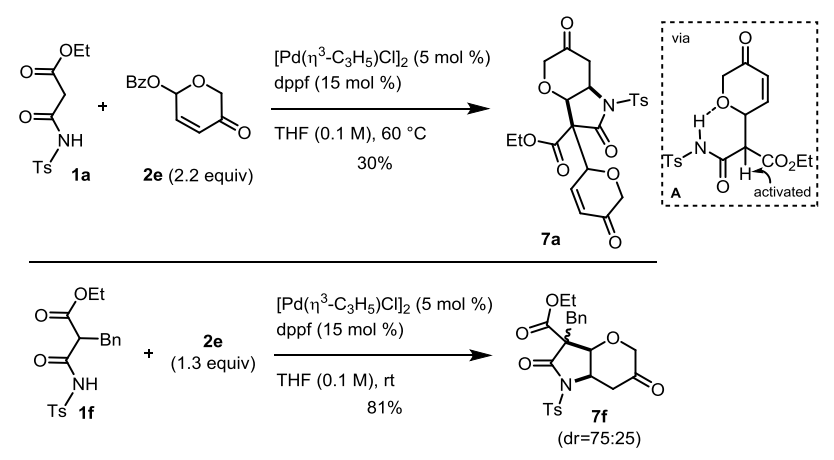

Finally, we reasoned that by using a bis-nucleophile bearing a juxtaposed halo-aryl moiety, the allylation / conjugate addition sequence could be coupled to an additional $\mathrm{Pd}$ catalyzed intramolecular arylation. ${ }^{20}$ The success of such an ambitious plan depends, inter alia, on the possibility of intramolecularly trapping the enolate issued from the nitrogen 1,4-addition with the catalytically generated arylpalladium(II) moiety, without premature proton transfer from the acid carbon atom of the bis-nucleophile component. With the above caveat in mind, ${ }^{21}$ we initially investigated the reaction between the bis-nucleophile 1s, bearing a methyl group on the $\alpha$-position, and bis-electrophile 2a (Scheme 6). After considerable experimentations (see SI), we found that treatment of the brominated bis-nucleophile 1s with cyclic $\alpha, \beta$-unsaturated- $\gamma$-oxy-carbonyl $\mathbf{2 a}$ in the presence of the system $\left[\mathrm{Pd}(\mathrm{OAc})_{2}(10 \mathrm{~mol} \%), \mathrm{dppb}(15 \mathrm{~mol} \%), \mathrm{DBU}(2\right.$ equiv)] in toluene at $\mathrm{rt}$ for $10 \mathrm{~min}$, followed by addition of $\mathrm{K}_{3} \mathrm{PO}_{4}$ and further $2 \mathrm{~h}$ heating $\left(145^{\circ} \mathrm{C}\right.$ oil bath in sealed tube), gave the desired cis/cis fused tricyclic compound 10s in $85 \%$ yield as major diastereoisomer, along with $7 \%$ yield of the minor diastereoisomer 10s' (Scheme 6). ${ }^{15}$

Scheme 6. Triple domino allylation / $N$-conjugate addition / enolate $\alpha$-arylation

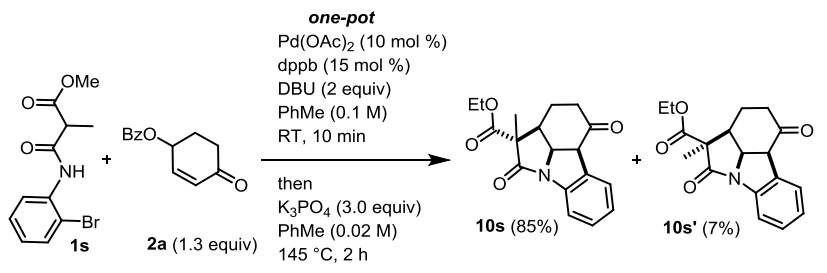

Following this satisfactory result, the triple domino process was tested using the unsubstituted amides bis-nucleophiles 1n, 1q, 1r, and 1j (Scheme 7). To our delight, the targeted tricycle compounds 10n, 10q and $10 \mathbf{r}^{22}$ were successfully isolated in good yields. In the case of $\mathbf{1 n}$, the tricycle was accompanied by a minor amount ( $6 \%$ yield) of the demethoxycarbonylated product 11n. The homologated bromo-benzyl derivative $\mathbf{1 j}$ led to the desired triple domino product $\mathbf{1 0 j}$, too. However, in this case, a prolonged reaction time was necessary and the major product consisted in the demethoxycarboylated product $\mathbf{1 1} \mathbf{j}$. It 
thus appears that the intramolecular arylation is sensibly easier for the formation of $6 / 5 / 5$ fused tricycles than $6 / 5 / 6$ ones.

Scheme 7. Triple domino allylation $/ N$-conjugate addition/enolate $\alpha$-arylation

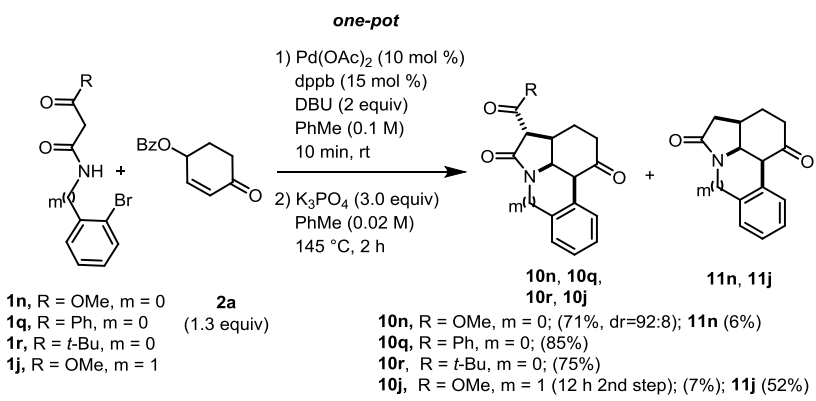

A plausible mechanism for this annulation is presented in Scheme 8 for the reaction between $\mathrm{N}$-o-bromophenyl amidoester 1n and 2-cyclohexenone 4-benzoate 2a. The sequence starts with an oxidative addition of the bis-electrophile $\mathbf{2 a}$ onto the $\operatorname{Pd}(0)$ complex to generate the corresponding transient $\eta^{3}$ allyl-complex $\mathbf{B}$ through the $\eta^{2}$-alkene complex $\mathbf{A}$ (steps $\underline{a}$ and $\underline{b})$. The amidinium-enolate of the bis-nucleophile $\mathbf{1},^{23,24}$ formed in the meantime (step $\underline{c}$ ), enters the catalytic cycle through C-allylation. Then, a new deprotonation by DBU and an oxidative addition of its aryl halide to $\operatorname{Pd}(0)$ generates amidate $\mathbf{C}($ step $\underline{d}) \cdot \operatorname{Pd}(0)$ decoordination (step e), to form $\mathbf{D}$, opens the way to the intramolecular aza-conjugate addition to afford bicyclic enolate $\mathbf{E}$ (step f). Subsequent enolatepalladation (step $g$ ) followed by reductive elimination generates the final tricyclic product $10 n$ and the $\operatorname{Pd}(0)$ complex. A notable feature of this process is the fact that the catalytic generation of the $\eta^{3}$-allyl-complex $\mathbf{B}$ completely wins against the alternative stoichiometric conjugate addition reactivity, a conditio sine qua non step chronology for the annulation. Indeed, a premature ( $\mathrm{N}$ or $\mathrm{C}$ ) conjugate addition reactivity would impede generation of the $\eta^{3}$-allyl-complex.
In conclusion, through the reaction between resonancestabilized acetamides as bis-nucleophiles and cyclic $\alpha, \beta$ unsaturated- $\gamma$-oxy-carbonyl derivatives as bis-electrophiles, we have successfully developed a new domino transformation consisting of an intermolecular Tsuji-Trost allylation / intramolecular nitrogen 1,4 addition sequence. The success of this [3+2] C-C/N-C bond forming annulation is due to the total chemoselectivity of the former step (C-allylation) as well as to the well-defined chronology of the following steps. When the newly formed annulation product contains an appropriately located ortho-haloaryl moiety at the nitrogen substituent, a further intramolecular keto $\alpha$-arylation can follow the cascade, thereby forming two new cycles and three new bonds in the same synthetic action. In view of the several synthetically interesting structures incorporating the bicyclic 4,5-fused pyrrolidine motif, such as lycorine-type alkaloids, ${ }^{25}$ daphniphyllum alkaloids ${ }^{26}$ and aeruginosins ${ }^{27}$ just to mention a few examples, and the many methods developed for the chemoselective and direct transformation of amides, ${ }^{28}$ the current method is expected to find wide application in organic synthesis. Further work is ongoing to develop enantioselective versions of this new transformation.

\section{ASSOCIATED CONTENT}

\section{Supporting Information}

The Supporting Information is available free of charge on the ACS Publications website. Further optimizations, experimental procedures, compound characterization (PDF).

\section{AUTHOR INFORMATION}

\section{Corresponding Author}

*E-mail: julie.oble@ sorbonne-universite.fr, giovanni.poli@ sorbonne-universite.fr

\section{ORCID}

Julie Oble: 0000-0002-4002-255X Giovanni Poli: 0000-0002-7356-1568

Pei-Qiang Huang: 0000-0003-3230-0457

Scheme 8. Plausible mechanism of domino Tsuji-Trost allylation / aza-Michael / keto $\alpha$-arylation

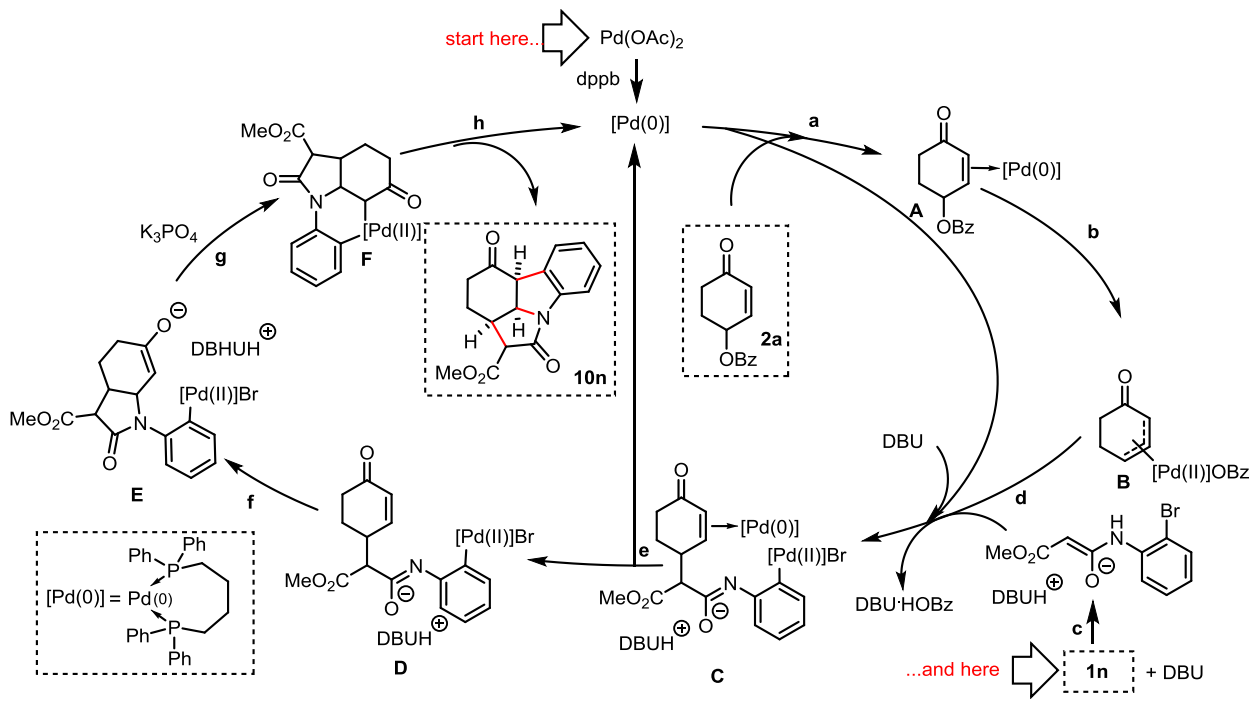




\section{ACKNOWLEDGMENT}

The authors would like to acknowledge Horizon 2020 ERANet-LAC project CelluloseSynThech for financial support, as well as CNRS, UPMC and Labex Michem (Investissements d'Avenir programme under reference ANR11-IDEX-0004-02). Support through CMST COST Action, CA15106 (CHAOS) is also gratefully acknowledged. We also thank L-M. Chamoreau and G. Gontard for the XRD analyses (IPCM) Y. L. thanks the China Scholarship Council for financial support.

\section{REFERENCE}

(1) (a) Tietze, L. F.; Brasche, G.; Gericke K. Domino Reactions in Organic Synthesis, Wiley-VCH: Weinheim, 2006. (b) Tietze, L. F. Chem. Rev. 1996, 96, 115. (c) Nicolaou, K. C.; Chen, J. S. Chem. Soc. Rev. 2009, 38, 2993. (d) Pellissier, H. Chem. Rev. 2013, 113, 442. (e) Kroutil, W.; Rueping, M. ACS Catal. 2014, 4, 2086.

(2) Wender, P. A.; Verma, V. A.; Paxton, T. J.; Pillow, T. H. Acc. Chem. Res. 2008, 41, 40.

(3) Diels, O. Alder, K. Liebigs Ann. Chem. 1928, 460, 98.

(4) Rapson, W. S.; Robinson, R. J. Chem. Soc. 1935, 1285.

(5) For a selection of articles focusing on annulations, see: (a) Bering, L.; Manna, S.; Antonchick, A. P. Chem. Eur. J. 2017, 23, 10936. (b) Gallier, F.; Martel, A. Dujardin, G. Angew. Chem. Int. Ed. 2017, 56, 12424. (c) Molander, G. A. Acc. Chem. Res. 1998, 31, 603

(6) For some examples, see: (a) Giboulot, S.; Liron, F.; Prestat, G.; Wahl, B.; Sauthier, M.; Castanet, Y.; Mortreux, A.; Poli, G. Chem. Commun. 2012, 48, 5889. (b) Lorion, M. M.; Gasperini, D.; Oble, J.; Poli, G. Org. Lett. 2013, 15, 3050. (c) Rigamonti, M.; Prestat, G.; Broggini, G.; Poli, G. J. Organomet. Chem. 2014, 760, 149. (d) Erray, I.; Rezgui, F.; Oble, J.; Poli, G. Synlett 2014, 25, 2196. (e) Kammerer, C.; Prestat, G.; Madec, D.; Poli, G. Acc. Chem. Res. 2014, 47, 3439 .

(7) Mao, Z.; Martini, E.; Prestat, G.; Oble, J.; Huang, P-Q.; Poli, G. Tetrahedron Lett. 2017, 58, 4174.

(8) (a) Prestat, G.; Poli, G. Chemtracts - Org. Chem. 2004, 17, 97. (b) Poli, G.; Giambastiani, G. J. Org. Chem. 2002, 67, 9456.

(9) For Pd-catalyzed sequences using the same bis-allylic substrate, see: (a) Trost, B. M.; Li, L.; Guile, S. D. J. Am. Chem. Soc. 1992, 114, 8745. (b) Yochizaki, H.; Satoh, H.; Sato, Y.; Nukui, S.; Shibasaki, M.; Mori, M. J. Org. Chem. 1995, 60, 2016. (c) Trost, B. M.; Surivet, J.-P. Angew. Chem., Int. Ed. 2000, 39, 3122. (d) Chapsal, B. D.; Ojima I. Org. Lett. 2006, 8, 1395.

(10) (a) Fürstner, A.; Feyen, F.; Prinz, H.; Waldmann, H. Tetrahedron 2004, 60, 9543. (b) Bartlett, M. J.; Turner, C. A.; Harvey, J. E. Pd-Catalyzed Allylic Alkylation Cascade with Dihydropyrans: Regioselective Synthesis of Furo[3,2-c]pyrans. Org. Lett. 2013, 15, 2430. (c) Kasare, S.; Bankar, S. K.; Ramasastry, S. S. V. Expeditious Metal-Free Access to Functionalized Polycyclic Acetals under Mild Aqueous Conditions. Org. Lett. 2014, 16, 4284. (d) Yu, J.; Ma, H.; Yao, H.; Cheng, H.; Tong, R. Diastereoselective and regiodivergent oxa-[3+2] cycloaddition of Achmatowicz products and cyclic 1,3-dicarbonyl compounds. Org. Chem. Front. 2016, 3, 714 .

(11) For the Pd-catalyzed oxidative desymmetrization of mesodibenzoates of cyclic bis-allylic systems and the synthetic exploitation of the resulting $\alpha, \beta$-unsaturated- $\gamma$-oxy-carbonyl compounds, see: Trost, B. M.; Masters, J. T.; Lumb, J.-P.; Fateen D. Chem. Sci. 2014, 5,1354

(12) For some examples of [3+2] C-C/N-C bond forming annulations, see: (a) Zhang, P.; Zhou, Y.; Han, X.; Xu, J.; Liu, H. J. Org. Chem. 2018, 83, 3879. (b) Yuan, S.; Luo, Y.; Peng, J.; Miao, M.; Xu, J.; Ren, H. Org. Lett. 2017, 19, 6100. (c) Narboni, N.; El Kaim,
L. Eur. J. Org. Chem. 2017, 4242. (d) Li, X-S.; Zhao, L-L.; Wang, XK.; Cuo, L-L.; Shi, X-Q.; Zhang, R.; Qi, J. Org. Lett. 2017, 19, 3943. (e) El Mamouni, E. H.; Cattoen, M.; Cordier, M.; Arseniyadis, S.; Ilitki, H.; El Kaïm L. Chem. Commun. 2016, 52, 14490. (f) Feng, J-J.; Zhang, J. ACS Catal. 2016, 6, 6651. (g) Specklin, S.; Decuypere, E.; Plougastel, L.; Aliani, S. Taran, F. J. Org. Chem. 2014, 79, 7772. (h) Li, E.; Jia, P.; Liang, L.; Huang Y. ACS Catal. 2014, 4, 600. (i) Wender, P. A.; Strand, D. J. Am. Chem. Soc., 2009, 131, 7528.

(13) Liu, Y.; Wang, X.; Xu, J.; Zhang, Q.; Zhao, Y.; Hu, Y. Tetrahedron 2011, 67, 6294.

(14) (a) Jyothi, D.; Prasad, S. H. Synlett 2009, 14, 2309. (b) Hayashi, Y.; Shoji, M.; Kistida, S. S. Tetrahedron Lett. 2005, 46, 681.

(15) The relative stereochemistry of the compound was ascertained by ${ }^{1} \mathrm{H}$ NMR NOESY and coupling constant analysis.

(16) $N$-methyl substitution and nitrile or nitro as resonance stabilizing group in the bis-nucleophile did not allow the desired annulation reaction.

(17) O’Byrne, A.; Murray, C.; Keegan, D.; Palacio, C.; Evans, P.; Morgan, B. S. Org. Biomol. Chem. 2010, 8, 539.

(18) Fujimoto, Y.; Xie, R.; Tully, S. E.; Berova, N.; Nakanishi, K. Chirality 2002, 14, 340.

(19) Takayama, H.; Jia, Z.-J.; Kremer, L.; Bauer, J. O.; Strohmann, C.; Ziegler, S.; Antonchick, A. P.; Waldmann, H. Angew. Chem. Int. Ed. 2013, 52, 12404.

(20) (a) Bellina, F.; Rossi, R. Chem. Rev. 2010, 110, 1082. (b) Culkin, D.; Hartwig, J. F. Acc. Chem. Res. 2003, 36, 234. For a recent example, see: (c) Casnati, A.; Maggi, R.; Maestri, G.; Della Ca', N.; Motti, E. J. Org. Chem. 2017, 82, 8296.

(21) Treatment of annulated products $\mathbf{3 j}$ and $\mathbf{3 n}$ with excess LDA and TBSOTf gave tricycle aldol adducts 9 in high yields (see SI). This result shows the difficulty of accomplishing a double depronation on this type of substrates, as the first generated resonance-stabilized enolate undergoes a fast intramolecular carbonyl addition, thereby impeding a second deprotonation in $\alpha$ position to the keto function.

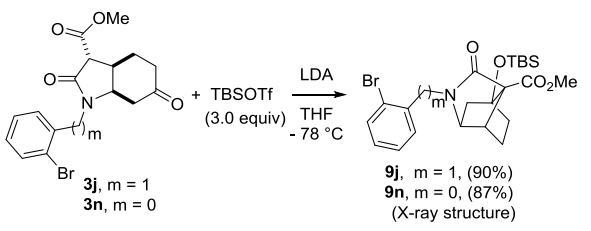

(22) The identity and the stereochemistry of compound $10 \mathrm{r}$ could be unambiguously proven by X-ray diffraction of a single crystal of it (see SI).

(23) We found the annulation very sensitive to proton transfer factors. Thus, while the $N$-sulfonyl bis-nucleophile based annulations could be achieved only in the absence of base, most of the $N$-alkyl based ones were successful only in the presence of base. In line with this pronounced proton transfer sensitivity, it is also remarkable that the formal introduction of an $o$-bromo or $o$-chloro (but not an $o$-iodo) substituent to the $N$-phenyl amido-ester permits base-free conditions.

(24) In the cases in which the base is not required, it is likely that the benzoate anion, counter-ion of the $\eta^{3}$-allylPd complex, acts as the base to deprotonate the pro-nucleophile. See: Giambastiani; G.; Poli, G. J. Org. Chem. 1998, 63, 9608.

(25) For a recent example, see: Chen, Y.-J.; Cai, S.-L.; Wang, C.-C.; Cheng, J.-D.; Kramer, S.; Sun, X.-W. Chem. Asian J. 2017, 12, 1309.

(26) (a) For a recent example, see: Shvartsbart, A.; Smith, A. B. J. Am. Chem. Soc. 2015, 137, 3510. (b) For a review, see: Kobayashi, J.; Kubota, T. Nat. Prod. Rep. 2009, 26, 936.

(27) (a) For a recent example, see: Scherer, M.; Bezold, D.; Gademann, K. Angew. Chem. Int. Ed. 2016, 55, 9427. (b) For a review, see: Ersmark, K.; Del Valle, J. R.; Hanessian, S. Angew. Chem. Int. Ed. 2008, 47, 1202. 
(28) (a) Kaiser, D.; Maulide, N. J. Org. Chem. 2016, 81, 4421. (b) Ruider, S. A.; Maulide, N. Angew. Chem. Int. Ed. 2015, 54, 13856. (c) Kaiser, D.; Teskey C. J.; Adler, P.; Maulide N. J. Am. Chem. Soc. 2017, 39, 16040. 